\title{
Comparison of the Mechanical Properties of Early Leukocyte- and Platelet-Rich Fibrin versus PRGF/Endoret Membranes
}

\author{
Hooman Khorshidi, ${ }^{1}$ Saeed Raoofi, ${ }^{1}$ Rafat Bagheri, ${ }^{2}$ and Hodasadat Banihashemi ${ }^{3}$ \\ ${ }^{1}$ Department of Periodontology, School of Dentistry, Shiraz University of Medical Sciences, Shiraz, Iran \\ ${ }^{2}$ Department of Dental Materials, School of Dentistry, Shiraz University of Medical Sciences, Shiraz, Iran \\ ${ }^{3}$ Periodontology Department, Faculty of Dentistry, Shahid Sadoughi University of Medical Sciences, Yazd, Iran \\ Correspondence should be addressed to Hodasadat Banihashemi; hoda.banihashemi@gmail.com
}

Received 19 July 2015; Revised 10 December 2015; Accepted 16 December 2015

Academic Editor: Andrija Bosnjak

Copyright (C) 2016 Hooman Khorshidi et al. This is an open access article distributed under the Creative Commons Attribution License, which permits unrestricted use, distribution, and reproduction in any medium, provided the original work is properly cited.

Objectives. The mechanical properties of membranes are important factors in the success of treatment and clinical handling. The goal of this study was to compare the mechanical properties of early leukocyte- and platelet-rich fibrin (L-PRF) versus PRGF/Endoret membrane. Materials and Methods. In this experimental study, membranes were obtained from 10 healthy male volunteers. After obtaining $20 \mathrm{cc}$ venous blood from each volunteer, $10 \mathrm{cc}$ was used to prepare early L-PRF (group 1) and the rest was used to get a membrane by PRGF-Endoret system (group 2). Tensile loads were applied to specimens using universal testing machine. Tensile strength, stiffness, and toughness of the two groups of membranes were calculated and compared by paired $t$-test. Results. The mean tensile strength and toughness were higher in group 1 with a significant difference $(P<0.05)$. The mean stiffness in group 1 was also higher but not statistically significant $(P>0.05)$. Conclusions. The results showed that early L-PRF membranes had stronger mechanical properties than membranes produced by PRGF-Endoret system. Early L-PRF membranes might have easier clinical handling and could be a more proper scaffold in periodontal regenerative procedures. The real results of the current L-PRF should be in fact much higher than what is reported here.

\section{Introduction}

Periodontal reconstruction is the ideal goal of periodontal treatment and since 1970, many researches led to developing various methods to achieve it. Among these methods, guided tissue regeneration (GTR) and guided bone regeneration (GBR) use barrier membranes to separate the periodontal ligament and bone from the epithelium and connective tissue which allow the former to regenerate the defects [1]. Recently, various growth factors have been studied in periodontal regeneration [2] and it is indicated that they might strongly alter the healing process [3]. A new method in this field is using concentrated platelet products which are the source of autologous platelet derived growth factors and transforming growth factors [4].
Among various concentrated platelet products, preparation rich in growth factor (PRGF) is an autologous plateletrich plasma product which accelerates local release of growth factors and bioactive proteins following its activation. With various formulations, this product can be used in form of liquid or in form of clot as a membrane which is a biocompatible, dense, and elastic membrane [5]. The new form of concentrated platelet is platelet-rich fibrin (PRF) that can be used directly as a clot or as a strong membrane after compression $[6,7]$. PRF as a membrane has shown slow release of growth factors such as vascular endothelial growth factor (VEGF), transforming growth factor (TGF- $\beta$ ), and platelet derived growth factor (PDGF) for at least 7 days in vitro [8]. Leukocyte- and platelet-rich fibrin (L-PRF) can be considered as a second-generation platelet concentrate. It forms a 


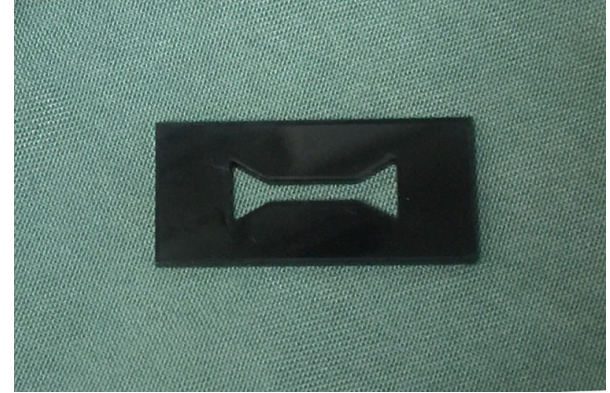

Figure 1: The dog-bone-shape plexiglass mold.

strong fibrin matrix with a complex three-dimensional architecture, in which most of the platelets and leucocytes from the harvested blood are concentrated [9]. Platelet-rich fibrin membranes can be used in various regenerative treatments $[10,11]$ to accelerate healing, to progress the regeneration process, and also as a scaffold in tissue engineering.

Besides scientific evidences about efficacy, for selection of an appropriate membrane, there are other important parameters including mechanical properties and clinical handling $[12,13]$. Mechanical characteristics of the membrane may affect the final results of GBR [14]. Tensile strength of a material when sutured may affect the clinical result of following healing [15]. Moreover strong mechanical characteristics of a scaffold provide a more suitable support for regeneration [16].

It is reported that increasing fibrinogen concentrates and adding calcium chloride increase the adhesion and tensile strength of fibrin clot [17]. It is also indicated that increasing thrombin and fibrinogen may increase the stiffness of fibrin matrix [18].

To the best of authors' knowledge, a comparison of mechanical characteristics of PRF and PRGF membranes is missing in previous studies. The goal of this study was to compare the mechanical properties of early L-PRF and the PRGF membranes. The null hypothesis was that there is no difference between mechanical properties of early L-PRF and PRGF membranes.

\section{Materials and Methods}

In this experimental study, $20 \mathrm{cc}$ venous blood was obtained from 10 healthy volunteer males with age range of 25 to 35 years. The exclusion criteria were suffering from a known systemic disease, history of taking any anticoagulant medication, smoking, and history of taking any medicine in the past 3 months.

2.1. Preparing a Mold. A specially designed plexiglass mold was fabricated to make the fibrin specimens identical in size, volume, and figure, following a modification of the dog-boneshape mold in Alston's study [17]. The thickness of the mold was $2 \mathrm{~mm}$ and the width was $2 \mathrm{~mm}$ in the narrow middle part and $6 \mathrm{~mm}$ in the larger ends. The total volume of the mold was $104 \mathrm{~mm}^{3}$. The narrow neck provided the weakest point where the specimen would break (Figure 1).

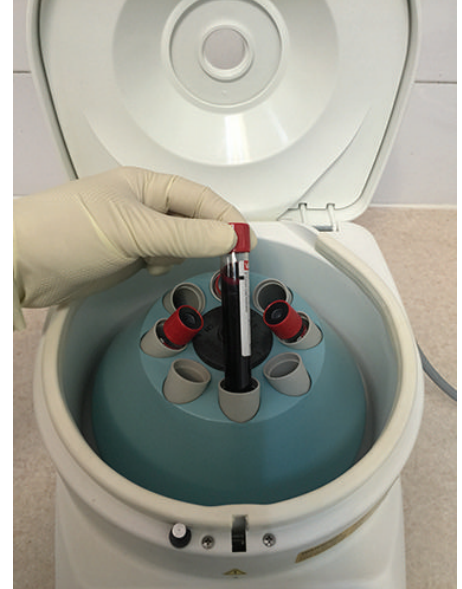

FIGURE 2: Tube containing blood in the centrifuge machine.

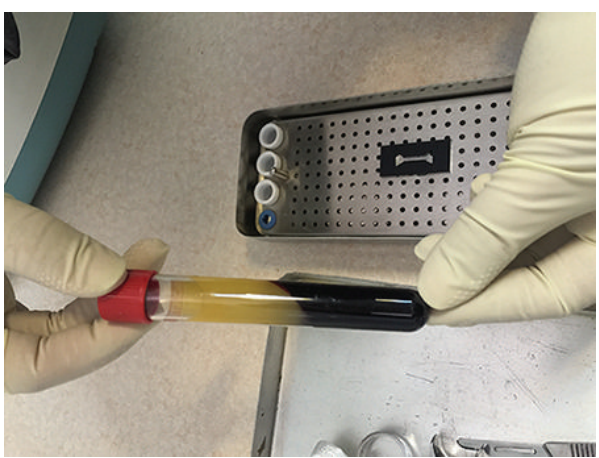

FIgURE 3: Tube containing early L-PRF after centrifuge.

2.2. Blood Collection. After obtaining informed consent approved by the ethical committee of Shiraz University of Medical Science (Grant number 92-01-03-6162) from all donors, $20 \mathrm{cc}$ venous blood was collected by sterile syringe. $10 \mathrm{cc}$ was placed in a dry sterile tube specific for PC-02 machine and the rest was divided into two $5 \mathrm{cc}$ blood samples placed in two tubes containing $0.5 \mathrm{cc} 3.8 \%$ concentrate of sodium citrate as anticoagulant specific for PRGF-Endoret system.

2.3. Preparing the Membranes. Platelet-rich membranes were obtained by two different protocols:

The first one was producing early L-PRF [7] by PC02 machine (Process Ltd., Nice, France) in which the tube that contained blood was centrifuged immediately after blood collection in speed of $400 \mathrm{gr}$ for 10 min [19] (Figure 2). The outcome was a fibrin clot containing platelets in the middle of the tube, between acellular plasma at the top and the red blood cell layer at the bottom (Figure 3 ). This clot was removed from the tube (Figure 4) and the attached red blood cells were scraped off and discarded. The early L-PRF clot was then placed in the mold (Figure 5) which was placed on the grid in the PRF Box [20] (Process 


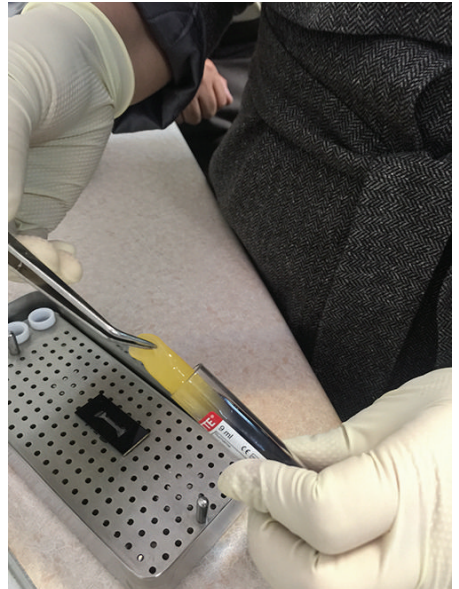

FIGURE 4: Removing the early L-PRF from the tube.

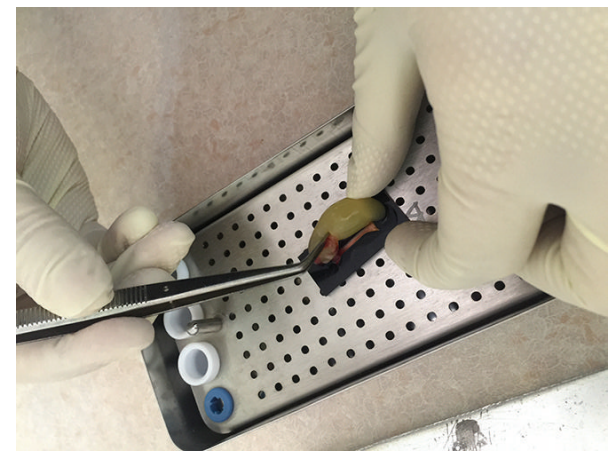

FIGURE 5: Placing the early L-PRF clot into the mold.

Ltd., Nice, France) (Figure 6) and covered with the compressor and lid. After 10 min the formed early LPRF membrane was prepared (Figure 7).

The second protocol was performed using PRGFEndoret system (BTI, Spain) (Figure 8). The two $5 \mathrm{cc}$ tubes were centrifuged in speed of $400 \mathrm{gr}$ for $8 \mathrm{~min}$ with BTI centrifuge machine (BTI, Spain) (Figure 9). Then each tube contained red blood cell at the bottom and plasma at the top with a thin layer of WBC in the middle (Figure 10). The inferior half of the plasma which was rich in platelets and growth factors was removed by plasma transfer device 2 (PTD2) (BTI, Spain) and placed in another tube. As the manufacturer instructions, $0.05 \mathrm{~mL}$ PRGF-Endoret activator per $1 \mathrm{~mL}$ plasma was added and then placed on incubator at $37^{\circ} \mathrm{C}$ for $30 \mathrm{~min}$ to obtain the clot (Figure 11). The clot was placed in the mold and after $10 \mathrm{~min}$ the formed membrane was obtained (Figure 12).

2.4. Tensile Test. Tensile test was performed using universal testing machine (Zwick/Roll Z020, Zwick GmbH \& Co., Germany) (Figure 13). The larger ends of the dog-bone shape specimen were held with the clips of the machine without any

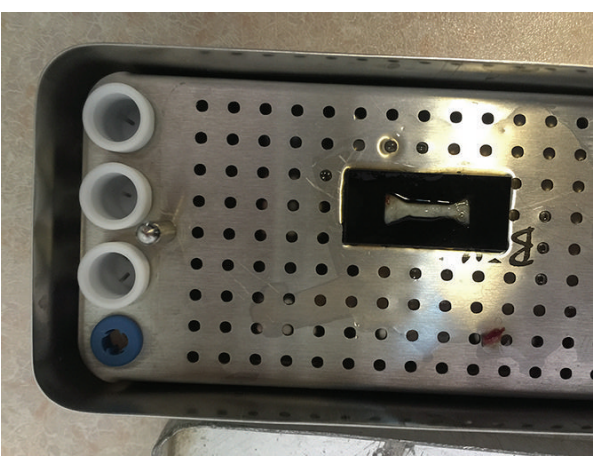

Figure 6: A fibrin specimen in the mold.

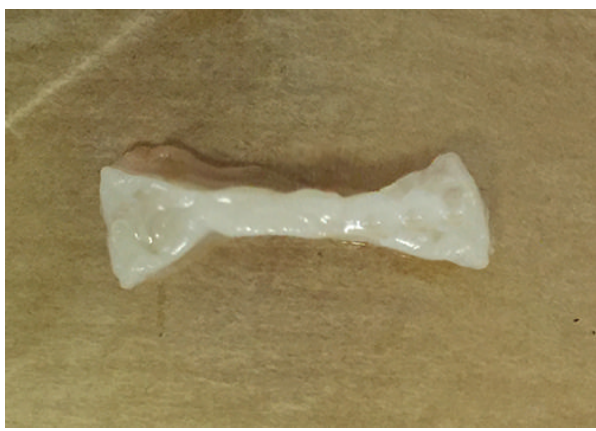

Figure 7: A formed specimen.

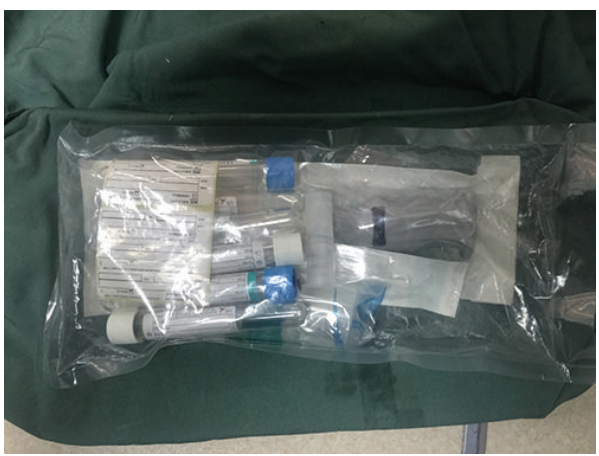

FIgURe 8: A BTI kit.

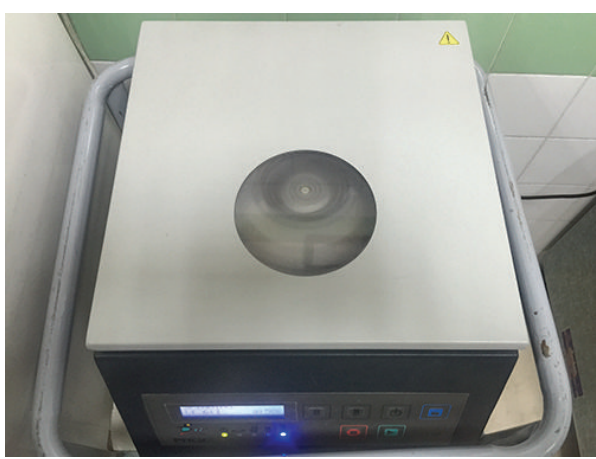

FIGURE 9: BTI centrifuging machine. 


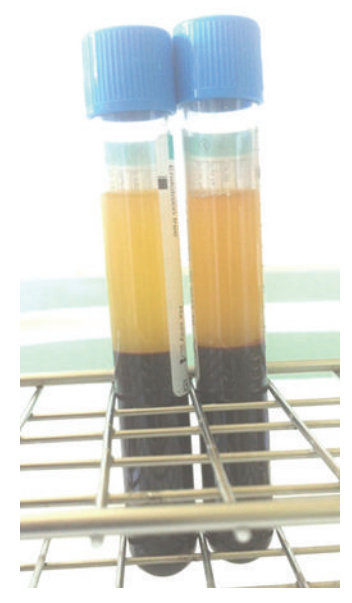

FIGURE 10: Tubes containing PRGF after centrifuge.

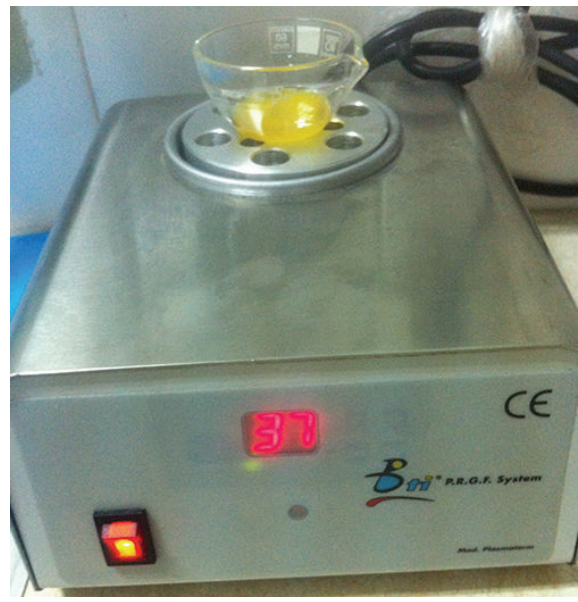

FIGURE 11: Mixture of the platelet-rich plasma and the activator on the incubator.

tension. Tensile loading was applied at a cross head speed of $2 \mathrm{~mm} / \mathrm{min}$; the maximum load at specimen failure was recorded and tensile strength was calculated using following formula: $S=F / A$, where $F$ is maximum force $(\mathrm{N})$ and $A$ is unit area $\left(\mathrm{m}^{2}\right)$.

Stress-strain curve was recorded with test Xpert II software simultaneously. Stiffness of the specimen (modulus of elasticity) was obtained by stress/strain and the total area under the curve designated as toughness of the specimens.

2.5. Data Analysis. Data were collected and analyzed using SPSS version 16; Student $t$-test was used to compare the groups: the early L-PRF as group 1 and the PRGF-Endoret system as group 2 .

\section{Results}

The results of all tests for two groups are summarized in Table 1.

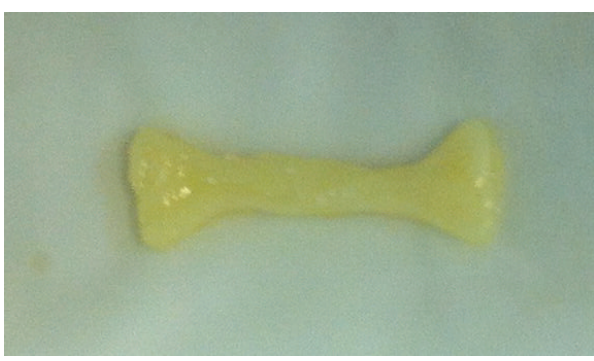

Figure 12: A formed specimen.

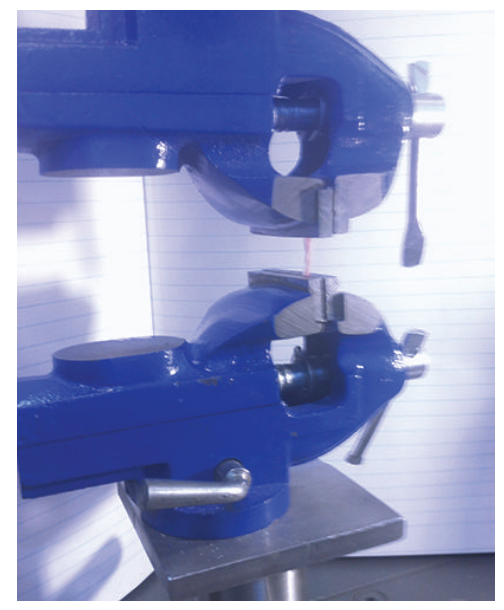

FIgURE 13: The universal testing machine.

TABLE 1: Mean values and standard deviation $( \pm S D)$ for all tested properties in the two groups.

\begin{tabular}{lccc}
\hline Measured values & Group & Mean $\pm \mathrm{SD}$ & $P$ value \\
\hline \multirow{2}{*}{ Tensile strength $(\mathrm{MPa})$} & 1 & $0.20 \pm 0.06$ & \multirow{2}{*}{0.049} \\
\hline \multirow{2}{*}{ Modulus of elasticity $(\mathrm{MPa})$} & 2 & $0.14 \pm 0.07$ & \\
\hline \multirow{2}{*}{ Toughness $\left(\mathrm{Joule} / \mathrm{m}^{3}\right)$} & 2 & $0.13 \pm 0.07$ & $0.11 \pm 0.09$ \\
& 1 & $1.87 \pm 0.61$ & \multirow{2}{*}{0.001} \\
\hline
\end{tabular}

Tensile strength of early L-PRF group with mean value of $0.20 \pm 0.06 \mathrm{MPa}$ was significantly higher than PRGF group with mean value of $0.14 \pm 0.07 \mathrm{MPa}(P=0.049)$. Early LPRF group was slightly stiffer than PRGF group but was not statistically significant $(P=0.69)$. Toughness of early L-PRF group was significantly higher than PRGF group $(P=0.001)$.

\section{Discussion}

This study experienced that the mechanical properties of early L-PRF membranes are stronger than the PRGF-Endoret membranes.

Platelet-rich fibrin membrane releases various growth factors such as PDGF, TGF- $\beta$, and VEGF slowly [21] and its supportive fibrin matrix plays an important role in its 
therapeutic effects [6]. The potential of platelet-rich membrane in accelerating regeneration has led to its application in various regenerative treatments like sinus floor elevation, ridge augmentation, socket preservation, root coverage, intrabony defects, and furcation defects [22-31]. It has been shown that fibrin membranes could be better scaffolds for proliferation of periosteal and osseous cells than collagen membranes in vitro $[32,33]$. The membranes that are used in regenerative procedures should have strong mechanical properties to protect blood clot and healing process [13]. As a scaffold, they provide better support against forces from infiltrating cells and adjacent tissues $[16,34]$.

The specimens of this study were selected from healthy male individuals with the age range of 25-35 to prevent possible bias from varieties in blood components of different sexes, ages, and systemic conditions. These issues were not considered together in the previous studies on fibrin clots $[17,35,36]$. The dog-bone-shape mold was used to make the specimens identical in size, volume, and shape. It was a modification of Alston's method [17], since the volume of clot we could obtain and consequently the volume of our specimen were lesser than Alston's study. Mechanical measurements were performed by universal testing machine as some other studies [17, 35-38].

According to the results of our study, the tensile strength, stiffness, and toughness of early L-PRF membranes were higher than the PRGF-Endoret membranes though the stiffness difference was not significant. This result may be due to their structural differences which may be affected by some factors like their differences in polymerization. The mode of polymerization has significant effects on mechanical properties of fibrin matrix [39]. This is consistent with the studies that evaluated their polymerization and internal structure [ 9 , 39]. The last stage of clotting, in which fibrinogen is converted to fibrin, can be accelerated by adding calcium chloride [40]. In PRGF-Endoret system, calcium chloride is used to initiate the last coagulation stage; then sudden fibrin polymerization occurs [39]. Therefore the fibrin matrix is immature and most of the fibrils are thin [9]. On the other hand, a slow and natural polymerization occurs during the centrifuge process in L-PRF producing method. The fibrin fibrillae can be assembled in 2 different biochemical architectures during gelling process: condensed tetramolecular or bilateral junctions and connected trimolecular or equilateral junctions [39]. PRGF mostly have the bilateral junctions which are weaker than the equilateral junctions [9] that are mostly found in L-PRF. This provides a flexible and elastic fibrin network [39]. L-PRF has thick fibers and strong matrix [9].

The density of the final fibrin matrix is another important factor that has an influence on the mechanical properties [41] and fibrinogen concentration affects this parameter. Fibrinogen mostly originates from the $\propto$-granules of the platelet in PRGF so the final fibrin has low density, while the circulating fibrinogen present in L-PRF strengthens the final fibrin matrix [9]. Alston et al. (2007) and Duong et al. (2009) indicated that increase in fibrinogen concentration makes the final fibrin matrix stronger $[17,18]$.

Another difference of these two membranes is the presence of large quantities of leukocytes in L-PRF and lack of them in PRGF. Some studies indicated that leukocytes have a key role in immune regulation, anti-infection properties [42-45], and angiogenesis [46] in platelet-rich concentrates. On the other hand, some authors claim that leukocytes may destroy the extracellular matrix of fibrin by the antiinflammatory effects of proteases and hydrolase; therefore they suggest removing the leukocytes from platelet-rich concentrates to prevent their negative effects on autologous fibrin formation $[5,47]$. The interaction of platelets and leukocytes in platelet-rich concentrates is not completely analyzed; they may also show synergistic effect [9]. Therefore the negative effects of leukocytes on fibrin matrix are controversial yet and our results suggest that these effects are not significant.

In producing the early L-PRF, no anticoagulant is employed but, in PRGF, sodium citrate is used. This difference of these two methods may affect the fibrin matrix. Kingston showed that high concentration of sodium citrate in blood samples decreases the ionized calcium of plasma leading to decrease in platelet accumulation and fibrinogen binding [48]. However, it is not obvious that $0.5 \mathrm{cc} 3.8 \%$ concentration of sodium citrate can have such an effect on PRGF matrix and controlled studies are needed to confirm this issue.

The room temperature during the process and the speed of centrifuge were the same in both groups but the duration was less in PRGF. Perez et al. showed that longer duration of centrifuge increases the platelet recovery [49] so this may affect the plasma components and final fibrin matrix properties.

Parameters such as manufacturing property of the blood collecting tubes and the pressure applied during the process do not affect the biomaterial structure [8].

It should be noted that we used the early protocol (3000 rpm, 10 minutes) to produce L-PRF, while since years the $2700 \mathrm{rpm} / 12$ minutes protocol is mostly used that gives much better polymerized L-PRF and therefore stronger membranes than the $3000 \mathrm{rpm} / 10 \mathrm{~min}$ protocol. The real results of the current L-PRF should be in fact much higher than what is reported here. However the material we used is adequate for the production of a good quality original L-PRF (early protocol). The original L-PRF system now exists only in one CE/FDA cleared form that is termed Intra-Spin L-PRF (Intra-lock, Boca Raton, FL, USA), and, legally, it is the only kit/system allowed in Western countries (CE/FDA).

\section{Conclusion}

Considering the limitations, this study showed that early LPRF membranes have stronger mechanical properties than platelet-rich membranes obtained by PRGF-Endoret system. Probably, they have easier clinical application and handling, and they may also be stronger during suturing and provide more supportive scaffold in periodontal regeneration. The real results of the current L-PRF should be in fact much higher than what is reported here.

\section{Conflict of Interests}

The authors declare that there is no conflict of interests regarding the publication of this paper. 


\section{Acknowledgments}

The authors thank the Vice-Chancellory of Research Shiraz University of Medical Science for supporting this research (Grant no. 92-01-03-6162). This paper is based on the thesis by Dr. Hodasadat Banihashemi. The authors also thank Dr. Mehrdad Vosooghi of the Dental Research Development Center, of the School of Dentistry, for the statistical analysis and Dr. Shahram Hamedani for his suggestions and editorial assistance in the paper.

\section{References}

[1] M. G. Newman, H. Takei, P. R. Klokkevold, and F. A. Carranza, Carranza's Clinical Periodontology, Elsevier Health Sciences, 2011.

[2] P. J. Boyne, R. E. Marx, M. Nevins et al., "A feasibility study evaluating rhBMP-2/absorbable collagen sponge for maxillary sinus floor augmentation," The International Journal of Periodontics \& Restorative Dentistry, vol. 17, no. 1, pp. 11-25, 1997.

[3] Z. Schwartz, D. L. Carnes Jr., R. Pulliam et al., "Porcine fetal enamel matrix derivative stimulates proliferation but not differentiation of pre-osteoblastic 2T9 cells, inhibits proliferation and stimulates differentiation of osteoblast-like MG63 cells, and increases proliferation and differentiation of normal human osteoblast NHOst cells," Journal of Periodontology, vol. 71, no. 8, pp. 1287-1296, 2000.

[4] R. E. Marx, E. R. Carlson, R. M. Eichstaedt, S. R. Schimmele, J. E. Strauss, and K. R. Georgeff, "Platelet-rich plasma: growth factor enhancement for bone grafts," Oral Surgery, Oral Medicine, Oral Pathology, Oral Radiology, and Endodontics, vol. 85, no. 6, pp. 638-646, 1998.

[5] E. Anitua, M. Sánchez, G. Orive, and I. Andia, "Delivering growth factors for therapeutics," Trends in Pharmacological Sciences, vol. 29, no. 1, pp. 37-41, 2008.

[6] M. Toffler, N. Toscano, D. Holtzclaw, M. Corso, and D. D. Ehrenfest, "Introducing Choukroun's platelet rich fibrin (PRF) to the reconstructive surgery milieu," The Journal of Implant \& Advanced Clinical Dentistry, vol. 1, no. 6, pp. 21-32, 2009.

[7] D. M. Dohan, J. Choukroun, A. Diss et al., "Platelet-rich fibrin (PRF): a second-generation platelet concentrate. Part I: technological concepts and evolution," Oral Surgery, Oral Medicine, Oral Pathology, Oral Radiology and Endodontology, vol. 101, no. 3, pp. E37-E44, 2006.

[8] D. M. Dohan Ehrenfest, G. M. de Peppo, P. Doglioli, and G. Sammartino, "Slow release of growth factors and thrombospondin-1 in Choukroun's platelet-rich fibrin (PRF): a gold standard to achieve for all surgical platelet concentrates technologies," Growth Factors, vol. 27, no. 1, pp. 63-69, 2009.

[9] D. M. D. Ehrenfest, L. Rasmusson, and T. Albrektsson, "Classification of platelet concentrates: from pure platelet-rich plasma (P-PRP) to leucocyte- and platelet-rich fibrin (L-PRF)," Trends in Biotechnology, vol. 27, no. 3, pp. 158-167, 2009.

[10] M. Del Corso, A. Vervelle, A. Simonpieri et al., "Current knowledge and perspectives for the use of Platelet-Rich Plasma (PRP) and Platelet-Rich Fibrin (PRF) in oral and maxillofacial surgery part 1: periodontal and dentoalveolar surgery," Current Pharmaceutical Biotechnology, vol. 13, no. 7, pp. 1207-1230, 2012.

[11] A. Simonpieri, M. Del Corso, A. Vervelle et al., "Current knowledge and perspectives for the use of platelet-rich plasma (PRP) and platelet-rich fibrin (PRF) in oral and maxillofacial surgery part 2: bone graft, implant and reconstructive surgery," Current Pharmaceutical Biotechnology, vol. 13, no. 7, pp. 12311256, 2012.

[12] J. Lindhe, T. Karring, and N. Lang, Clinical Periodontology and Implant Dentistry, Blackwell Munksgaard Blackwell Publishing, Oxford, UK, 5th edition, 2008.

[13] Y. Zhang, X. Zhang, B. Shi, and R. Miron, "Membranes for guided tissue and bone regeneration," Annals of Oral \& Maxillofacial Surgery, vol. 1, no. 1, article 10, 2013.

[14] S.-B. Lee, J.-S. Kwon, Y.-K. Lee, K.-M. Kim, and K.-N. Kim, "Bioactivity and mechanical properties of collagen composite membranes reinforced by chitosan and $\beta$-tricalcium phosphate," Journal of Biomedical Materials Research Part B: Applied Biomaterials, vol. 100, no. 7, pp. 1935-1942, 2012.

[15] J. B. Herrmann, "Changes in tensile strength and knot security of surgical sutures in vivo," Archives of Surgery, vol. 106, no. 5, pp. 707-710, 1973.

[16] S. E. Lynch, Tissue Engineering: Applications in Oral and Maxillofacial Surgery and Periodontics, Quintessence Publishing Company, 2008.

[17] S. M. Alston, K. A. Solen, A. H. Broderick, S. Sukavaneshvar, and S. F. Mohammad, "New method to prepare autologous fibrin glue on demand," Translational Research, vol. 149, no. 4, pp. 187-195, 2007.

[18] H. Duong, B. Wu, and B. Tawil, "Modulation of 3D fibrin matrix stiffness by intrinsic fibrinogen-thrombin compositions and by extrinsic cellular activity," Tissue Engineering-Part A, vol. 15, no. 7, pp. 1865-1876, 2009.

[19] D. M. D. Ehrenfest, M. Del Corso, A. Diss, J. Mouhyi, and J.B. Charrier, "Three-dimensional architecture and cell composition of a Choukroun's platelet-rich fibrin clot and membrane," Journal of Periodontology, vol. 81, no. 4, pp. 546-555, 2010.

[20] D. M. D. Ehrenfest, "How to optimize the preparation of leukocyte- and platelet-rich fibrin (L-PRF, Choukroun's technique) clots and membranes: introducing the PRF Box," Oral Surgery, Oral Medicine, Oral Pathology, Oral Radiology and Endodontology, vol. 110, no. 3, pp. 275-278, 2010.

[21] J. Gottlow, S. Nyman, T. Karring, and J. Lindhe, "New attachment formation as the result of controlled tissue regeneration," Journal of Clinical Periodontology, vol. 11, no. 8, pp. 494-503, 1984.

[22] J. Choukroun, A. Diss, A. Simonpieri et al., "Platelet-rich fibrin (PRF): a second-generation platelet concentrate. Part V: histologic evaluations of PRF effects on bone allograft maturation in sinus lift," Oral Surgery, Oral Medicine, Oral Pathology, Oral Radiology and Endodontology, vol. 101, no. 3, pp. 299-303, 2006.

[23] Z. Mazor, R. A. Horowitz, M. Del Corso, H. S. Prasad, M. D. Rohrer, and D. M. D. Ehrenfest, "Sinus floor augmentation with simultaneous implant placement using Choukroun's plateletrich fibrin as the sole grafting material: a radiologic and histologic study at 6 months," Journal of Periodontology, vol. 80, no. 12, pp. 2056-2064, 2009.

[24] F. Inchingolo, M. Tatullo, M. Marrelli et al., "Trial with plateletrich fibrin and Bio-Oss used as grafting materials in the treatment of the severe maxillar bone atrophy: clinical and radiological evaluations," European Review for Medical and Pharmacological Sciences, vol. 14, no. 12, pp. 1075-1084, 2010.

[25] M. Del Corso, M. Toffler, and D. Dohan Ehrenfest, "Use of an autologous leukocyte and platelet-rich fibrin (L-PRF) membrane in post-avulsion sites: an overview of Choukroun's PRF," The Journal of Implant \& Advanced Clinical Dentistry, vol. 1, no. 9, pp. 27-35, 2010. 
[26] J.-H. Zhao, C.-H. Tsai, and Y.-C. Chang, "Clinical and histologic evaluations of healing in an extraction socket filled with platelet-rich fibrin," Journal of Dental Sciences, vol. 6, no. 2, pp. 116-122, 2011.

[27] B. I. Simon, P. Gupta, and S. Tajbakhsh, "Quantitative evaluation of extraction socket healing following the use of autologous platelet-rich fibrin matrix in humans," The International Journal of Periodontics \& Restorative Dentistry, vol. 31, no. 3, pp. 285295, 2011.

[28] K. Anilkumar, A. Geetha, Umasudhakar, T. Ramakrishnan, R. Vijayalakshmi, and E. Pameela, "Platelet-rich-fibrin: a novel root coverage approach," Journal of Indian Society of Periodontology, vol. 13, no. 1, pp. 50-54, 2009.

[29] S. Aroca, T. Keglevich, B. Barbieri, I. Gera, and D. Etienne, "Clinical evaluation of a modified coronally advanced flap alone or in combination with a platelet-rich fibrin membrane for the treatment of adjacent multiple gingival recessions: a 6-month study," Journal of Periodontology, vol. 80, no. 2, pp. 244-252, 2009.

[30] Y.-C. Chang and J.-H. Zhao, "Effects of platelet-rich fibrin on human periodontal ligament fibroblasts and application for periodontal infrabony defects," Australian Dental Journal, vol. 56, no. 4, pp. 365-371, 2011.

[31] A. Sharma and A. R. Pradeep, "Autologous platelet-rich fibrin in the treatment of mandibular degree II furcation defects: a randomized clinical trial," Journal of Periodontology, vol. 82, no. 10, pp. 1396-1403, 2011.

[32] V. Gassling, T. Douglas, P. H. Warnke, Y. Açil, J. Wiltfang, and S. T. Becker, "Platelet-rich fibrin membranes as scaffolds for periosteal tissue engineering," Clinical Oral Implants Research, vol. 21, no. 5, pp. 543-549, 2010.

[33] V. Gassling, J. Hedderich, Y. Açil, N. Purcz, J. Wiltfang, and T. Douglas, "Comparison of platelet rich fibrin and collagen as osteoblast-seeded scaffolds for bone tissue engineering applications," Clinical Oral Implants Research, vol. 24, no. 3, pp. 320-328, 2013.

[34] T. E. Orr, P. A. Villars, S. L. Mitchell, H.-P. Hsu, and M. Spector, "Compressive properties of cancellous bone defects in a rabbit model treated with particles of natural bone mineral and synthetic hydroxyapatite," Biomaterials, vol. 22, no. 14, pp. 1953-1959, 2001.

[35] E. Lucarelli, R. Beretta, B. Dozza et al., "A recently developed bifacial platelet-rich fibrin matrix," European Cells and Materials, vol. 20, pp. 13-23, 2010.

[36] J. L. Velada, D. A. Hollingsbee, A. R. Menzies, R. Cornwell, and R. A. Dodd, "Reproducibility of the mechanical properties of Vivostat system patient-derived fibrin sealant," Biomaterials, vol. 23, no. 10, pp. 2249-2254, 2002.

[37] S. L. Rowe, S. Lee, and J. P. Stegemann, "Influence of thrombin concentration on the mechanical and morphological properties of cell-seeded fibrin hydrogels," Acta Biomaterialia, vol. 3, no. 1, pp. 59-67, 2007.

[38] B. Blombäck and N. Bark, "Fibrinopeptides and fibrin gel structure," Biophysical Chemistry, vol. 112, no. 2-3, pp. 147-151, 2004.

[39] R. V. Kumar and N. Shubhashini, "Platelet rich fibrin: a new paradigm in periodontal regeneration," Cell and Tissue Banking, vol. 14, no. 3, pp. 453-463, 2013.

[40] M. H. Boyer, J. R. Shainoff, and O. D. Ratnoff, "Acceleration of fibrin polymerization by calcium ions," Blood, vol. 39, no. 3, pp. 382-387, 1972.
[41] T. Kawase, K. Okuda, L. F. Wolff, and H. Yoshie, "Plateletrich plasma-derived fibrin clot formation stimulates collagen synthesis in periodontal ligament and osteoblastic cells in vitro," Journal of Periodontology, vol. 74, no. 6, pp. 858-864, 2003.

[42] P. A. M. Everts, A. van Zundert, J. P. A. M. Schönberger, R. J. J. Devilee, and J. T. A. Knape, "What do we use: plateletrich plasma or platelet-leukocyte gel?” Journal of Biomedical Materials Research-Part A, vol. 85, no. 4, pp. 1135-1136, 2008.

[43] A. Cieslik-Bielecka, T. S. Gazdzik, T. M. Bielecki, and T. Cieslik, "Why the platelet-rich gel has antimicrobial activity?" Oral Surgery, Oral Medicine, Oral Pathology, Oral Radiology, and Endodontology, vol. 103, no. 3, pp. 303-305, 2007.

[44] D. J. F. Moojen, P. A. Everts, R. M. Schure et al., "Antimicrobial activity of platelet-leukocyte gel against Staphylococcus aureus," Journal of Orthopaedic Research, vol. 26, no. 3, pp. 404-410, 2008.

[45] H. El-Sharkawy, A. Kantarci, J. Deady et al., "Platelet-rich plasma: growth factors and pro- and anti-inflammatory properties," Journal of Periodontology, vol. 78, no. 4, pp. 661-669, 2007.

[46] K. Werther, I. J. Christensen, and H. J. Nielsen, "Determination of Vascular Endothelial Growth Factor (VEGF) in circulating blood: significance of VEGF in various leucocytes and platelets," Scandinavian Journal of Clinical \& Laboratory Investigation, vol. 62, no. 5, pp. 343-350, 2002.

[47] E. Anitua, M. Sánchez, G. Orive, and I. Andía, “The potential impact of the preparation rich in growth factors (PRGF) in different medical fields," Biomaterials, vol. 28, no. 31, pp. 45514560, 2007.

[48] J. K. Kingston, W. M. Bayly, D. C. Sellon, K. M. Meyers, and K. J. Wardrop, "Effects of sodium citrate, low molecular weight heparin, and prostaglandin $\mathrm{E}_{1}$ on aggregation, fibrinogen binding, and enumeration of equine platelets," American Journal of Veterinary Research, vol. 62, no. 4, pp. 547-554, 2001.

[49] A. G. Perez, J. F. S. Lana, A. A. Rodrigues, A. C. M. Luzo, W. D. Belangero, and M. H. A. Santana, "Relevant aspects of centrifugation step in the preparation of platelet-rich plasma," ISRN Hematology, vol. 2014, Article ID 176060, 8 pages, 2014. 


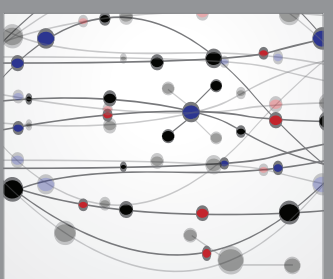

The Scientific World Journal
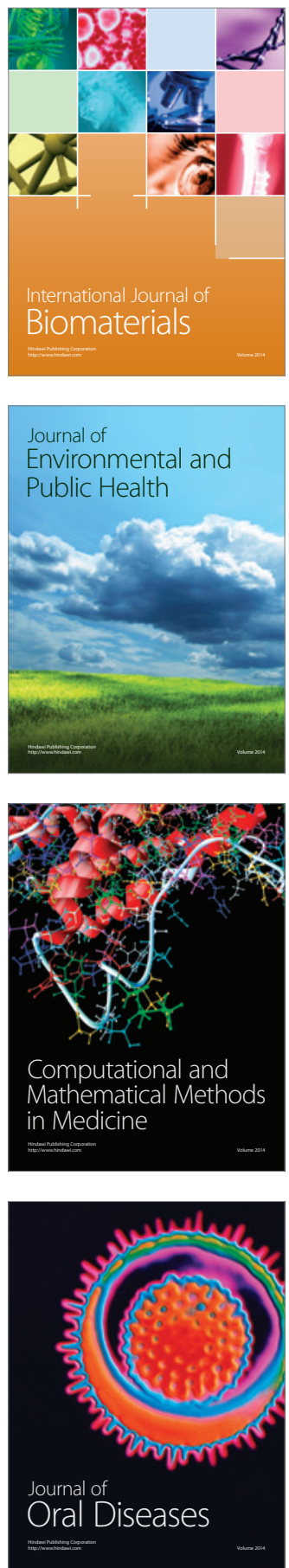
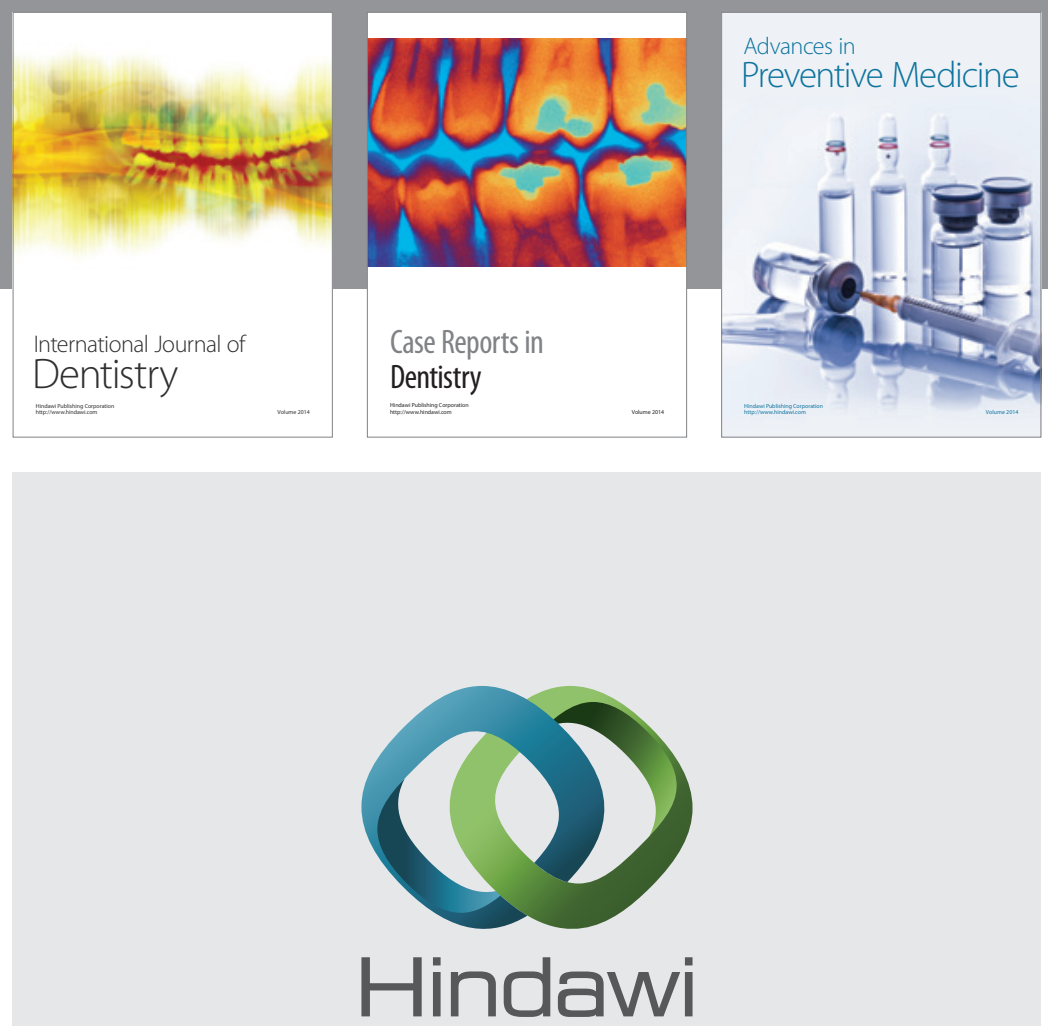

Submit your manuscripts at

http://www.hindawi.com
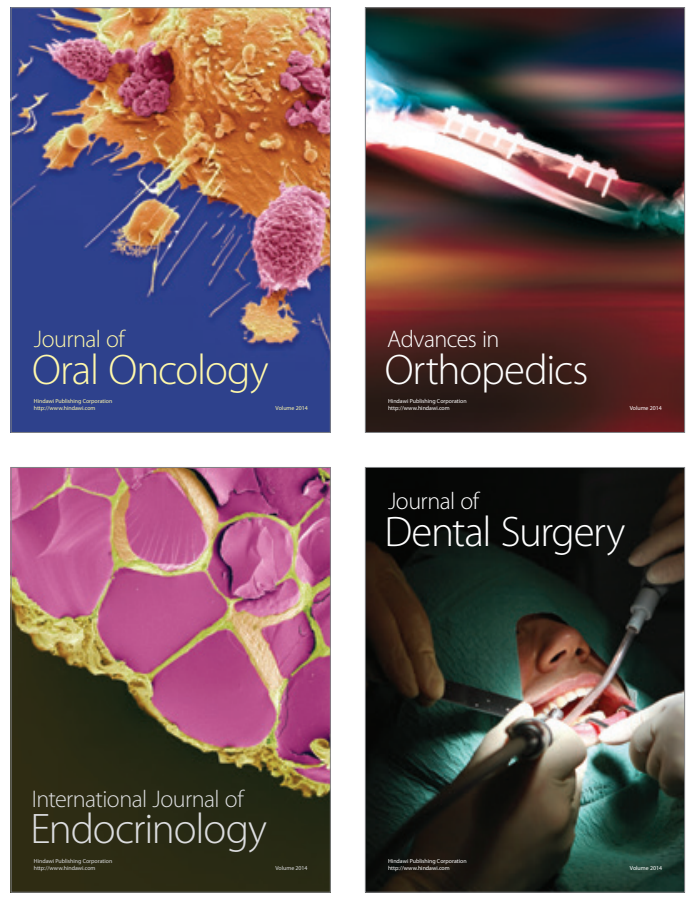
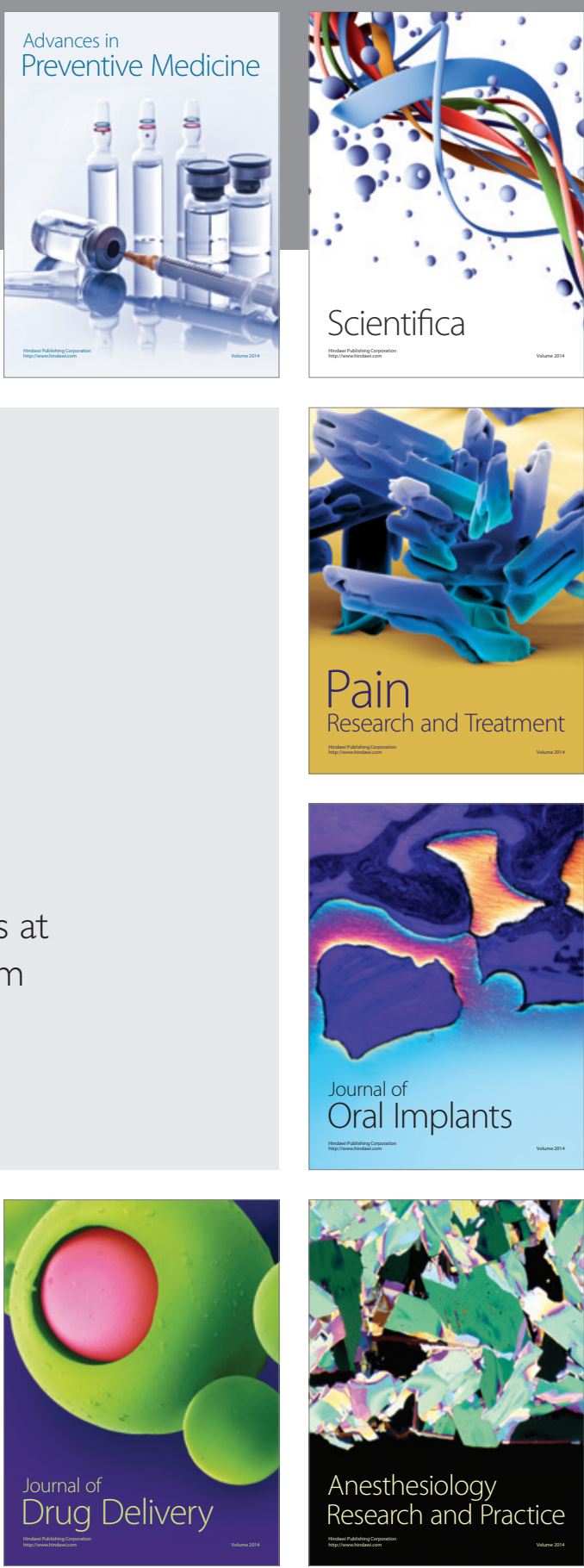

Scientifica
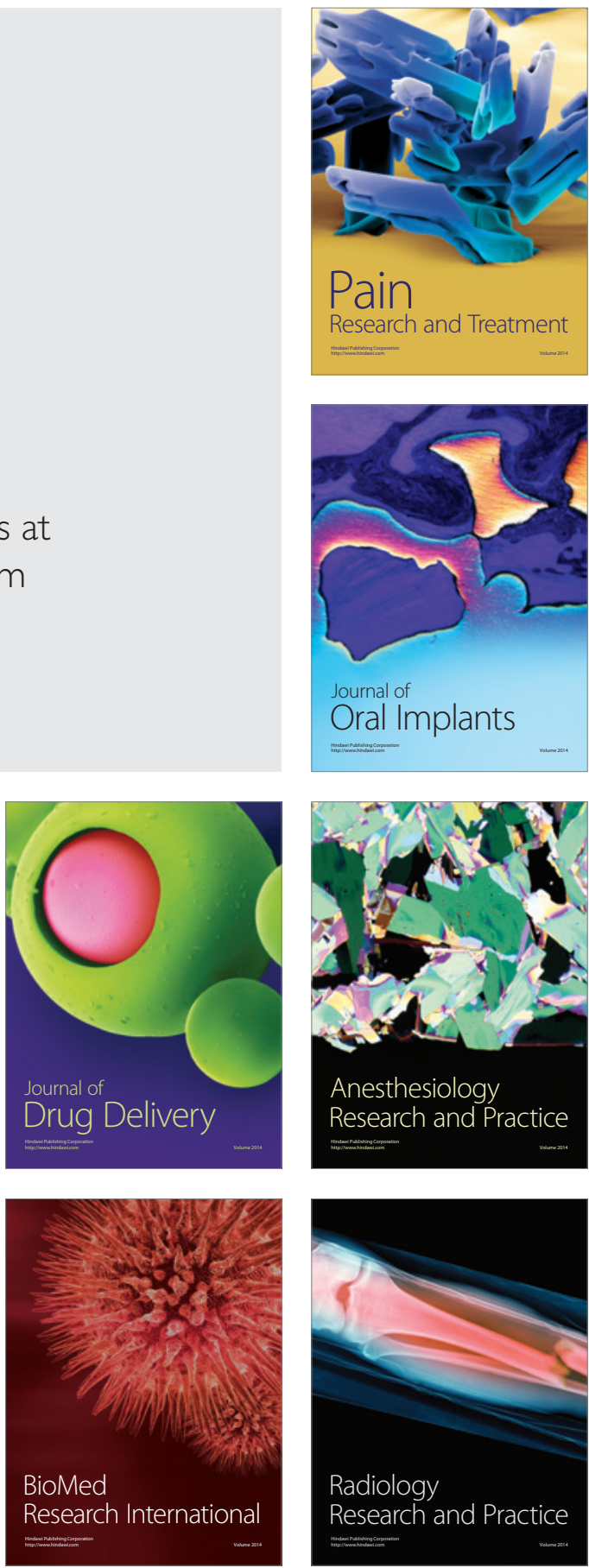